PNL-SA-24416

\title{
MODELING OF THE SIMULATED COUNTERCURRENT MOVING-BED CHROMATOGRAPHIC REACTOR USED FOR THE OXIDATIVE COUPLING OF METHANE
}

\author{
A. L. Y. Tonkovich \\ R. W. Carr
}

September 1994

Presented at the

13th Annual Symposium on Chemical Reaction

Engineering Conference

September 25-28, 1994

Baltimore, Maryland

Prepared for

the U.S. Department of Energy

under Contract DE-AC06-76RLO 1830

Pacific Northwest Laboratory

Richland, Washington 99352

\section{DISCLAIMER}

\begin{abstract}
This report was prepared as an account of work sponsored by an agency of the United States Government. Neither the United States Government nor any agency thereof, nor any of their employees, makes any warranty, express or implied, or assumes any legal liability or responsibility for the accuracy, completeness, or usefulness of any information, apparatus, product, or process disclosed, or represents that its use would not infringe privately owned rights. Reference herein to any specific commercial product, process, or service by trade name, trademark, manufacturer, or otherwise does not necessarily constitute or imply its endorsement, recommendation, or favoring by the United States Government or any agency thereof. The views and opinions of authors expressed herein do not necessarily state or reflect those of the United States Government or any agency thereof.
\end{abstract}

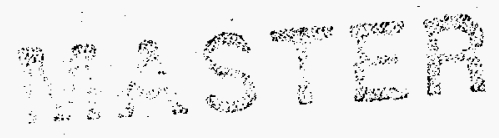




\section{DISCLAIMER}

Portions of this document may be illegible in electronic image products. Images are produced from the best available original document. 
Modeling of the Simulated Countercurrent Moving-Bed Chromatographic Reactor

Used for the Oxidative Coupling of Methane

Anna Lee Y. Tonkovich

Pacific Northwest Laboratory, Richland, WA 99352

Robert W. Carr

Department of Chemical Engineering and Materials Sciences

University of Minnesota, Minneapolis MN 55455

\begin{abstract}
:
The oxidative coupling reaction of methane (OCM) is a potential industrial reaction for the efficient production of ethylene. Replacement of current technologies requires significant product yield improvements. An experimental novel reactor design, the modified simulated countercurrent moving-bed chromatographic reactor (SCMCR), has reported improved ethane and ethylene product yields over other reported values (Tonkovich et al. 1993). An understanding of the reactor operation is aided by concurrent mathematical modeling.

The model mimics the exact experimental reactor configuration. Four sections are used; each section contains a reaction column and two separation columns connected in series. The feed is switched from section to section at discrete intervals. Reaction occurs in the first column and is followed by product and reactant separation in the ensuing section columns. Langmuir adsorption isotherms are used. The model does not incorporate the realistic and complex kinetics rising from the OCM, rather a simplified reaction term is used to qualitatively gain insight into the operation of the modified SCMCR.
\end{abstract}

A unimolecular reaction network is used in the model. The rate constants are set to permit a small fractional conversion, $5 \%$ per pass, at the concentrations during the first cycle. Similarly to the experimental reactor, the model adds a make-up feed (defined as percentage of the original feed, where excess methane is fed during the first cycle of the experimental reactor) to augment lost reactants.

The effects of the switching time and the make-up feed rate are investigated. For a breakthrough time of $34 \mathrm{sec}$ and a make-up feed rate of $15 \%$, a parabolic dependence between conversion and switching time is observed. This agrees with experimental behavior where a 
maximum is observed as a function of switching time. A conversion as high as $60 \%$ is predicted for these operating parameters. A parabolic effect with make-up feed rate is also observed. A maximum conversion of $60 \%$ occurs at a make-up feed rate of $12.5 \%$.

The model qualitatively predicts the experimentally observed behavior. Experimentally, the optimal performance is observed with switching times between $80 \%$ and $90 \%$ of the original feed breakthrough time. This is validated by the model.

\section{Introduction:}

The simulated countercurrent chromatographic reactor and separator ( $\mathrm{SCMCR}$ ) is an experimental novel reactor design, and has demonstrated enhanced ethane and ethylene yields for the oxidative coupling reaction of methane (OCM). The experimental reactor required significant design modifications to be applicable for reactions such as the OCM. To guide the experimental investigations and increase the understanding of the reactor operation, a mathematical model incorporating the exact experimental reactor configuration was developed.

This paper describes the experimental novel reactor and the corresponding mathematical model used to determine the feasibility of this design. The model evaluates the applicability of low conversion per pass reactions such as the OCM. The model is also extended to qualitatively reproduce the experimental trends observed in the modified SCMCR and investigate other important experimental parameters.

\section{Background:}

A mathematical model describing the operation of the original simulated countercurrent reactor and separator has been described (Ray et al. 1990, 1994). This continuous model was developed for the mesitylene dehydrogenation reaction and showed enhanced product yields for equilibriumlimited reactions from the SCMCR.

Many mathematical modeis have been developed to describe simulated countercurrent separators (SCCS). Inclusion of a simultaneous reaction is an extension of this work. 
Plate models:

- Non-continuous moving feed (Ha et al. 1987a-b)

- Semi-continuous moving feed (Barker et al. 1983; Hidajat et al. 1986b)

- Continuous SCCS (Ernst and Hsu 1989; Storti et al. 1989; Ching and Ruthven 1985, Ruthven 1984; Ruthven and Ching 1989; Hidajat et al. 1986a)

- True countercurrent (Storti et al. 1989; Barker 1971)

\section{Differential models:}

- Continuous intermittent moving bed (Hashimoto et al. 1983a-b, 1987; Kishihara et al. 1989; Storti et al. 1988; Kubota et al. 1989; Svedberg 1976; Maki et al. 1987; Ruthven and Ching 1989).

- Discontinuous moving bed (McGary and Wankat 1983)

- True countercurrent (Hashimoto et al. 1983b, 1985; Ruthven 1983, 1984; Ruthven and Ching 1989; Ching et al. 1991; Rhee et al. 1971, 1986; Storti et al. 1988; Hidajat et al. 1986a)

\section{Model Development:}

The experimental apparatus of the SCMCR required significant modifications to be applicable for some reactions, including the OCM. This simple model was developed to evaluate the applicability of the modified design for low conversion reactions like oxidative coupling.

The model evaluates a simple first-order and reversible $(A \Leftrightarrow B)$ equilibrium-limited reaction. The products adsorb more strongly than the reactants. The experimental apparatus has four sections within the reactor and each section is comprised of separate reaction and separation columns. The theoretical configuration of these columns matches the experimental design (Tonkovich et al. 1993, 1994), as shown in Figure 1. After the first column switching, a makeup feed (taken as a percentage of the original feed) is added to the reactor. Although the 
assumption of a first-order reversible reaction is not valid for the oxidative coupling reaction, this model gives insight into the operation of this novel reactor for low conversion per pass reactions.

The mass balance equations for both the components in both the gas and solid phases are developed. The simple mass balance equations exclude dispersion effects, include a heterogeneous surface reaction, and account for Langmuir adsorption and desorption between the two phases in the separation columns. Isothermal operation is also assumed. The equations are shown in Equations (1-4)

mobile (gas) phase:

$$
\begin{array}{cc}
\varepsilon \frac{\partial c_{A}}{\partial t}+\varepsilon u \frac{\partial c_{A}}{\partial z}+(1-\varepsilon) k_{a A}\left(N-n_{A}-n_{B}\right) c_{A}-(1-\varepsilon) k_{d A} n_{A}=0 & \begin{array}{l}
\text { desorption } \\
\text { accumulation } \\
\text { convection solid }
\end{array} \\
\begin{array}{l}
\text { adsorption } \\
\text { onto solid }
\end{array} & \frac{\partial c_{B}}{\partial t}+\varepsilon u \frac{\partial c_{B}}{\partial z}+(1-\varepsilon) k_{a B}\left(N-n_{A}-n_{B}\right) c_{B}-(1-\varepsilon) k_{d B} n_{B}=0
\end{array}
$$

stationary (solid) phase:

$$
\begin{aligned}
& \frac{\partial n_{A}}{\partial t}-k_{a A}\left(N-n_{A}-n_{B}\right) c_{A}+k_{d A} n_{A}-\alpha_{A}\left(k_{f} n_{A}-k_{b} n_{B}\right)=0 \\
& \begin{array}{lll}
\text { accumulation } & \text { adsorption } & \text { desorption surface reaction } \\
\text { onto solid } & \text { from solid }
\end{array} \\
& \frac{\partial n_{B}}{\partial t}-k_{a B}\left(N-n_{A}-n_{B}\right) c_{B}+k_{d B} n_{B}-\alpha_{B}\left(k_{f} n_{A}-k_{b} n_{B}\right)=0
\end{aligned}
$$

The mass balance equations are simplified and solved numerically. A fourth-order RungeKutta solving technique (Nauman 1986) is used to solve the partial differentials in time, while the differentials in space are solved by a backwards Euler's approximation. The mass balances are simplified before the application of the numerical solution. The simplified equations reduce to Equations (5-8)

mobile (gas) phase:

$$
\frac{\partial c_{A}}{\partial t}+v \frac{\partial c_{A}}{\partial \zeta}+\lambda k_{a A}\left(1-\Theta_{A}-\Theta_{B}\right) c_{A}-\lambda k_{d A} \Theta_{A}=0
$$




$$
\begin{array}{ccc}
\text { accumulation } & \begin{array}{c}
\text { convection } \\
\text { adsorption } \\
\text { onto solid }
\end{array} & \begin{array}{c}
\text { desorption } \\
\text { from solid }
\end{array} \\
\frac{\partial c_{B}}{\partial t}+v \frac{\partial c_{B}}{\partial \zeta}+\lambda k_{\mathrm{B}}\left(1-\Theta_{A}-\Theta_{B}\right) c_{B}-\lambda k_{d B} \Theta_{B}=0
\end{array}
$$

stationary (solid) phase:

$$
\begin{aligned}
& \frac{\partial \Theta_{A}}{\partial t}-k_{a A}\left(1-\Theta_{A}-\Theta_{B}\right) c_{A}+k_{d A} \Theta_{A}-\rho_{A}\left(K_{e q} \Theta_{A}-\Theta_{B}\right)=0 \\
& \begin{array}{lll}
\text { accumulation } & \begin{array}{l}
\text { adsorption } \\
\text { onto solid }
\end{array} & \begin{array}{l}
\text { desorption } \\
\text { from solid }
\end{array}
\end{array} \\
& \frac{\partial \Theta_{B}}{\partial t}-k_{a B}\left(1-\Theta_{A}-\Theta_{B}\right) c_{B}+k_{d B} \Theta_{B}-p_{B}\left(K_{e q} \Theta_{A}-\Theta_{B}\right)=0
\end{aligned}
$$

The value of the dimensionless distance variable difference $(\Delta \zeta)$ is taken as the size of a theoretical plate; the equations are solved simultaneously at every time step in each plate to calculate the new component concentrations. The vectorized program runs on a Cray-XMP and iterates from feed switch to feed switch until a periodic steady-state is approached.

The program iterates to the total number of preset column switches. The sum of the products produced during the cycle and the reactants lost during that same cycle are calculated. The amount of material removed is used to calculate the average conversion during the switching cycle. All concentrations are then moved one column to the right to simulate a column switch that occurs in the experimental apparatus.

The conversion is calculated comparing the summation of the reactant losses and the summation of the products produced to the feed added during each cycle. When the program achieves a cyclic steady-state operation, the conversion is nearly equal using both calculation techniques. For most trials, the computed concentration profiles are still changing slightly after 40,60 ; and even 80 switches. Once the conversion calculations are within several percent of each other, the net conversion is taken as the average of the two calculations. Small time steps ( 2 milliseconds) are necessary to ensure a stable and converged solution. 


\section{Model paraneter values:}

The model generates qualitative generalizations about the performance of this novel reactor design with a low conversion per pass reaction. The values of the model parameters are obtained from single column OCM experimental results. The gas velocity is set equal to the experimental value $\left(5 \mathrm{~cm} / \mathrm{sec}--100 \mathrm{~cm}^{3} / \mathrm{min}\right.$ with an internal cross sectional area of approximately $\left..3 \mathrm{~cm}^{2}\right)$. The carrier gas velocity in the product section is set many times greater than that in the feed and carrier sections. A larger gas velocity is needed to completely remove all of the products left in the product section.

The gas phase adsorption and desorption rate constants are varied until they produce exiting component concentration profiles that match experiments. The adsorption rate constants are set equal for both components, but the reactant desorption rate constant is larger to produce the desired elution order. This ratio of desorption rate constants was varied until the difference in breakthrough times of the two components equal those found in the experimental system, a factor of eight. A reactant breakthrough time of $34 \mathrm{sec}$ (also experimental value) requires 262 plates in the combined separation columns and 20 plates in the reaction column. The location of the product removal port, for most trials, is placed at the 170 plate, which is approximately $65 \%$ down the separation column. The reaction parameters (equilibrium constant and backward rate constant) are set at $\left(.05\right.$ and $\left.90 \mathrm{~s}^{-1}\right)$ so that the conversion per pass roughly matches experimental values.

The location of the product removal port is not placed at the $170^{\text {th }}$ plate for all trials. The position of the product port is moved up and down slightly (between $50 \%$ and $70 \%$ of the overall separation section) for some trials. Changing the port does not have an effect on the overall conversion calculated for the reactor, but it does have an effect upon the product purity.

\section{Results and Discussion:}

The performance of the SCMCR is evaluated with this model. The model predicts a significant increase in the overall reactor conversion. Although the premise of the model is based on a 
different type of reaction than that used experimentally (the OCM) the model is still useful. The oxidative coupling reaction has a low reactant conversion per pass similar to an equilibrium-limited reaction. The model evaluates the effect of the subsequent integrated separation columns that follow the reaction columns. The effluent concentrations that leave the reaction column are theoretically the same either from an equilibrium-limited reaction or non-equilibrium-limited reaction. Thus, the effects of the cyclically discretized reaction and separation operations on the performance are evaluated and are independent of the reaction mechanism.

\section{Effect of the feed switching time:}

The switching time is an important parameter for determining the performance of the SCMCR. Using a conversion per pass of $5 \%$, a make-up feed of $15 \%$, and a reactant breakthrough time of $34 \mathrm{sec}$, the switching time is evaluated at several values between 20 and $34 \mathrm{sec}$, see Figure 2 . The reactant conversion is a strong function of switching time; a similar functional dependence is observed experimentally. Pseudo-parabolic relationships between conversion and switching time are observed. A sharp pseudo-parabolic curve is calculated numerically, while a broad diffuse relationship is observed experimentally. This difference is not unexpected because of the simplicity of the theoretical approach, which neglects dispersion and other peak broadening effects.

The conversion is lowest when the switching time is very near the breakthrough time or when it is much lower than the breakthrough time. An optimal switching time (31.25 sec) exists for these theoretical trials. Two competing sources of reactant losses produce the pseudo-parabolic behavior. At switching times less than the component breakthrough time, a significant amount of material is lost in the purge stream. The reactant entering the feed section during the final seconds of the switching cycle (the exact number of seconds is defined as the breakthrough time less the switching time) does not have enough time to elute from this section during the next cycle. If the sorbed reactant is not completely desorbed with the carrier stream, it is lost in a purge stream after the next switching. Conversely, at switching times near the breakthrough time, the reactant is also lost in a purge stream. A higher make-up feed rate is added than that needed to replace the material 
reacted in the feed column. As the reactant concentrates, Langmuir isotherms dictate an increase in elution velocity and thus breakthrough time.

The two competing loss terms give rise to an intermediate optimal value of the switching time. This optimal value is $31.25 \mathrm{sec}$ or $92 \%$ of the breakthrough time for the set of reactor operating parameters chosen.

Figures 3 through 5 show several cyclic steady-state component concentration profiles. These figures represent a 'snapshot' of the concentration profiles prior to a column switching for switching times of $31.5,25$, and $33 \mathrm{sec}$. These times represent values that are near, shorter than, and longer than the optimal switching time; respectively.

The initial normalized feed is set to one and the make-up feed is set at $15 \%$ of the original feed rate. Figures 3 and 4 show the largest reactant losses at a switching time of $25 \mathrm{sec}$. The fewest reactant losses are observed at $31.5 \mathrm{sec}$, which is near the optimal switching time.

At switching times much faster than the reactant breakthrough time, more reactant is lost. The material sorbed in one cycle does not have enough time to desorb during the next cycle, and will be lost in a subsequent purge stream. Figure 5 shows the concentration profiles in the separation column of the carrier section prior to a column switching. The reactant remaining in this section will be lost to a purge stream. The product remaining in this section wili be removed in the product removal section. The switching time nearest the optimal value has the largest amount of products remaining in this section. The fewest remaining products are observed for a switching time of 25 sec.

\section{Effect of the make-up feed rate:}

The make-up feed rates are varied to determine their effect on the optimal reactor performance. It is difficult to alter the make-up feed rates experimentally (below 10-15\%) because of the equipment limitations; therefore, this information is useful to predict the experimental behavior in this regime. The parameters remain identical to those used in the previous trials except for variations in the make-up feed rate. Figure 6 shows the effect of the make-up feed rate at 
switching times of 25,30 , and $32 \mathrm{sec}$, respectively. A strong interaction between the make-up feed rate and the reactor conversion is observed. An equilibrium-limited reaction with a 5\% per pass conversion shows an increase up to $60 \%$ total conversion.

At switching times $(25 \mathrm{sec}$ ) far below the breakthrough time ( $34 \mathrm{sec})$, the overall conversion has approximately a linear relationship with the make-up feed rate. As the make-up feed rate increases, the performance of the reactor improves. A pseudo-parabolic functional dependence between the conversion and make-up feed rate that exists for longer switching times does not exist for switching times well below the optimal switching time. The switching time is low enough such that even large values of the make-up feed flowrate do not concentrate the material within the feed section. The material that sorbs during any given short cycle does not have time to later completely desorb. For this trial, $25 \mathrm{sec}$ switching time, the material that adsorbs during the final seconds of a feed cycle requires $34 \mathrm{sec}$, but only has $25 \mathrm{sec}$ to completely desorb from the carrier section. This material is left behind and lost in a purge stream, which lowers the overall conversion.

At a switching time (32 sec) near the optimal switching time ( $31.25 \mathrm{sec}$ ), a pseudo-parabolic interaction between the conversion and the make-up feed rate is observed. The optimal make-up feed rate is $12.5 \%$ of the original feed, which corresponds to an overall conversion of $60 \%$. This functional dependence occurs because of two competing terms. As the make-up feed rate increases significantly, the reactant concentrates. Faster convective velocities and elution times are a result of Langmuir isotherms and create additional reactant losses. Conversely, at very low values of the make-up feed rate, there is not enough material added during each cycle to augment reactant losses. At intermediate make-up feed rates, the competing effects create an optimal make-up feed rate.

Finally, the effect of the make-up feed rate on the overall reactor conversion for a switching time of $30 \mathrm{sec}$ shows that the conversion rises dramatically with small changes in the make-up feed rate. As the rate increases above $23 \%$, the material concentrates significantly and a converged and stable solution can not be reached. It is predicted that the behavior at higher make-up feed rates will also give a pseudo-parabolic dependence because the material is concentrating above the 
original feed rate. As the material concentrates, it convectively moves faster and should elute from the feed section more quickly, thus creating additional reactant losses.

\section{Conclusions:}

The simulated countercurrent chromatographic reactor and separator (SCMCR) is shown theoretically to produce dramatic increases in the overall reactor conversion. Reactions with a low conversion per pass, on the order of $5 \%$, experience conversion increases to $60 \%$, which translates to a conversion that is 12 times larger than the equilibrium-limited case.

The models incorporate equilibrium-limited reactions with a low conversion per pass. Although the reaction of interest, oxidative coupling of methane to ethane and ethylene, is not an equilibrium-limited reaction, it does have a low per pass conversion. The model is successful in evaluating the modified reactor design, and predicts the same pseudo-parabolic functional dependence between conversion and switching time that is seen experimentally. The dependence of conversion on the make-up feed rate is also a function of the switching time. At switching times near the optimal value, or near the reactant breakthrough time, the conversion has a pseudoparabolic dependence similar to the effect seen with switching time. For switching times far less than the breakthrough time, the conversion has an approximately linear function with make-up feed rate, and does not exhibit parabolic-like behavior.

In general, the SCMCR is an excellent tool to enhance the overall conversion of reactions with a low conversion per pass. This reactor also acts to produce a very pure product stream, thus eliminating the need for an additional separation scheme.

\section{Acknowledgments:}

This work was supported by the Division of Chemical Sciences, Office of Basic Energy Sciences, U.S. Department of Energy, under contract DE-AC02-76-ER02945.

The Pacific Northwest Laboratory is operated by Battelle Memorial Institute for the U.S. Department of Energy under contract DE-AC06-76RLO 1830. 


\section{Nomenclature:}

$\varepsilon \quad$ void fraction (fraction gas occupies)

$\mathrm{c}_{\mathrm{A}}$ gas phase concentration of the reactant (A)

$\mathrm{C}_{\mathrm{B}}$ gas phase concentration of the product (B)

$\mathrm{u}$ gas phase velocity

$\mathrm{n}_{\mathrm{A}}$ solid phase concentration of the reactant

$\mathrm{n}_{\mathrm{B}}$ solid phase concentration of the product

$\mathrm{k}_{\mathrm{aA}}$ adsorption rate constant of the reactant onto the solid

$\mathrm{k}_{\mathrm{dA}}$ desorption rate constant of the reactant from the solid

$\mathrm{k}_{\mathrm{aB}}$ adsorption rate constant of the product onto the solid

$k_{\mathrm{dB}}$ desorption rate constant of the product from the solid

$\alpha_{A}-1$ for the reactant

$\alpha_{B}+1$ for the product

$k_{f}$. rate constant of the forward reaction

$\mathrm{k}_{\mathrm{b}}$ rate constant of the backward reaction

\section{Model parameters:}

$\zeta \quad \mathrm{z} / \mathrm{L}$, where $\mathrm{L}=$ column length

v $u / L$

$\Theta_{A} \quad n_{A} / N$, where $N=$ initial concentration of sites

$\Theta_{\mathrm{B}} \quad \mathrm{n}_{\mathrm{B}} / \mathrm{N}$

$\lambda \quad(1-\varepsilon) N / \varepsilon, \varepsilon=$ void fraction

$\rho_{A} \quad \alpha_{A} k_{b}$

$\rho_{B} \quad \alpha_{B} k_{b}$

$\mathrm{K}_{\text {eq }} \quad \mathrm{k}_{\mathrm{f}} / \mathrm{k}_{\mathrm{b}}$ (equilibrium constant) 


\section{References:}

Barker, P., 1971, Continuous chromatographic refining, Chapter 4, Progress in Separation and Purification, Wiley-Interscience Publishers, New York, 325.

Barker, P., England, K., and Vlachogiannis, G., 1983, Mathematical model for the fractionation of Dextran on a semi-continuous countercurrent simulated moving bed chromatograph, Chem. Eng. Res. Dev., 61,.

Ching, C. B., and Ruthven, D. M., 1985, An experimental study of a simulated countercurrent adsorption system, I. Isothermal steady-state operation, Chem. Eng. Sci., 40(6), 877.

Ching, C., Chu, K., Hidajat, K., and Uddin, M., 1991, Experimental and modeling studies on the transient behavior of a simulated countercurrent adsorber, J. Chem. Eng. Jap., 24(5), 614.

Ernst, U., and Hsu, J., 1989, Study of simulated moving-bed separation processes using a staged model, Ind. Eng. Chent. Res., 28, 1211.

Ha, H., Row, K., and Lee, W., 1987a, A plate model for moving feed-injection chromatography. I. Simulation results, Sep. Sci. Technol., 22(1), 141.

Ha, H., Row, K., and Lee, W., 1987b, A plate model for moving feed -injection chromatography. II. Experimental results", Sep. Sci. Technol., 22(4), 1281.

Hashimoto, K., Adachi, S., Noujima, H., and Maruyama, H., 1983a, Models for the separation of glucose/fructose mixtures using a simulated moving-bed adsorber, J. Chem. Eng. Jap., 16(5), 400 .

Hashimoto, K., Adachi, S., Noujima, H., and Ueda, Y., 1983b, A new process combining adsorption and enzyme reaction for producing higher-fructose syrup, Biotech. Bioeng., XXV, 2371 .

Hashimoto, K., Miura, K., and Kyotani, S., 1985, Regeneration of activated carbons used in waste-water treatment by a moving-bed regenerator, AIChE J., 31(12), 1986.

Hashimoto, K., Yamada, M., Shirai, Y., and Adachi, S., 1987, Continuous separation of glucose-salts mixtures with nonlinear and linear adsorption isotherms by using a simulated moving bed adsorber, J. Cliem. Eng. Jap., 20(4), 405.

Hidajat, K., Ching, C., and Ruthven, D., 1986a, Simulated countercurrent adsorption processes: a theoretical analysis of the effect of subdividing the adsorbent bed, Chem. Eng. Sci., 41(11), 2953.

Hidajat, K., Ching, C., and Ruthven, D., 1986b, Numerical simulation of a semi-continuous counter-current adsorption unit for fructose-glucose separation", Chem. Eng. J., 33, B55.

Kishihara, S., Horikawa, H., Tamaki, H., Fujii, S., Nakajima, Y., and Nishio, K., 1989, Continuous chromatographic separation of palatinose and trehalulose using a simulated movingbed adsorber, J. Chem. Eng. Jap., 22(4), 434.

Kubota, K., Hata, C., and Hayashi, S., 1989, A study of a simulated moving bed adsorber based on the axial dispersion model, Can. J. Chem. Eng, 67, 1025. 
Maki, H., Fukuda, H., and Morikawa, H., 1987, The separation of glutathione and glutamic acid using a simulated moving-bed adsorber system, J. Ferm. Techmol., 65(1), 61 .

McGary, R., and Wankat, P., 1983, Improved preparative liquid chromatography: the moving feed point method, $I \&$ EC Fun., 22(1), 10.

Nauman, E., 1986, Chemical Reactor Design, Wiley-Interscience Publishers, New York.

Ray, A., Tonkovich, A. L., Aris, R., and Carr, R. W., 1990, The simulated countercurrent moving bed chromatographic reactor, Chem. Eng. Sci., 45(8), 2431.

Ray, A., Carr, R., Aris, R., 1994, The simulated countercurrent moving bed chromatographic reactor: a novel reactor-separator, Chem. Eng. Sci., 49(4), 469.

Rhee, H., Aris, A., and Amundson, N., 1971, Multicomponent adsorption in continuous countercurrent exchangers, Proc. Roy. Soc. Lon., 269(1194), 187.

Rhee, H., Aris, A., and Amundson, N., 1986, First-Order Partial Differential Equations: Volume I. Theory and Applications of Single Equations, Prentice-Hall Publishers, New York.

Ruthven, D., 1983, The axial dispersed plug flow model for continuous countercurrent adsorbers", Can. J. Chem. Eng., 61.

Ruthven, D., 1984, Principles of Adsorption and Adsorption Processes, Chapter 12, WileyInterscience Publishers, New York.

Ruthven, D., and Ching, C., 1989, Counter-current and simulated counter-current adsorption separation processes", Chem. Eng. Sci., 44(5), 1011.

Storti, G., Masi, M., Paludetto, R., Morbidelli, M., and Carra, S., 1988, Adsorption separation processes: countercurrent and simulated countercurrent operations, Comp. Chem. Eng., 12(5), 475.

Storti, G., Masi, M., and Carra, S., 1989, Optimal design of multicomponent countercurrent adsorption separation processes involving nonlinear equilibria, Chem. Eng. Sci., 44(6), 1329.

Svedberg, U., 1976, Numerical solution of multicolumn adsorption processes under periodic countercurrent operation, Chem. Eng. Sci., 31, 345.

Tonkovich, A., Carr, R., and Aris, R., 1993, Enhanced C2 yields from methane oxidative coupling by means of a separative chemical reactor, Science, 262, 221.

Tonkovich, A., and Carr, R., 1994, A Simulated Countercurrent Moving-Bed Chromatographic Reactor for the Oxidative Coupling of Methane: Experimental Results, submitted to Chem. Eng. Sci. 


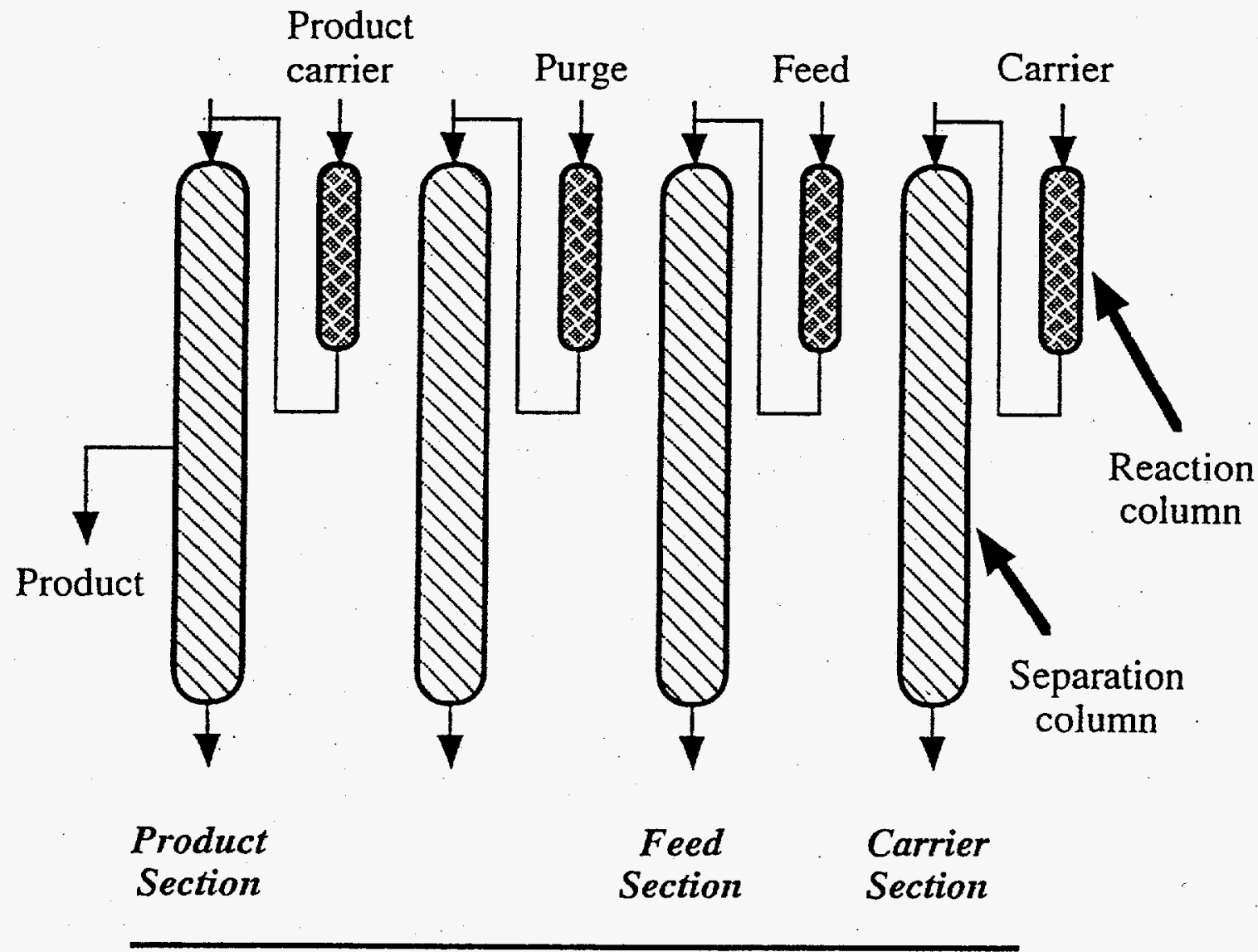

All ports move one column to the left at each switching time

Figure 1: Experimental apparatus containing four sections; each section contains a reaction column followed by a separation column. 


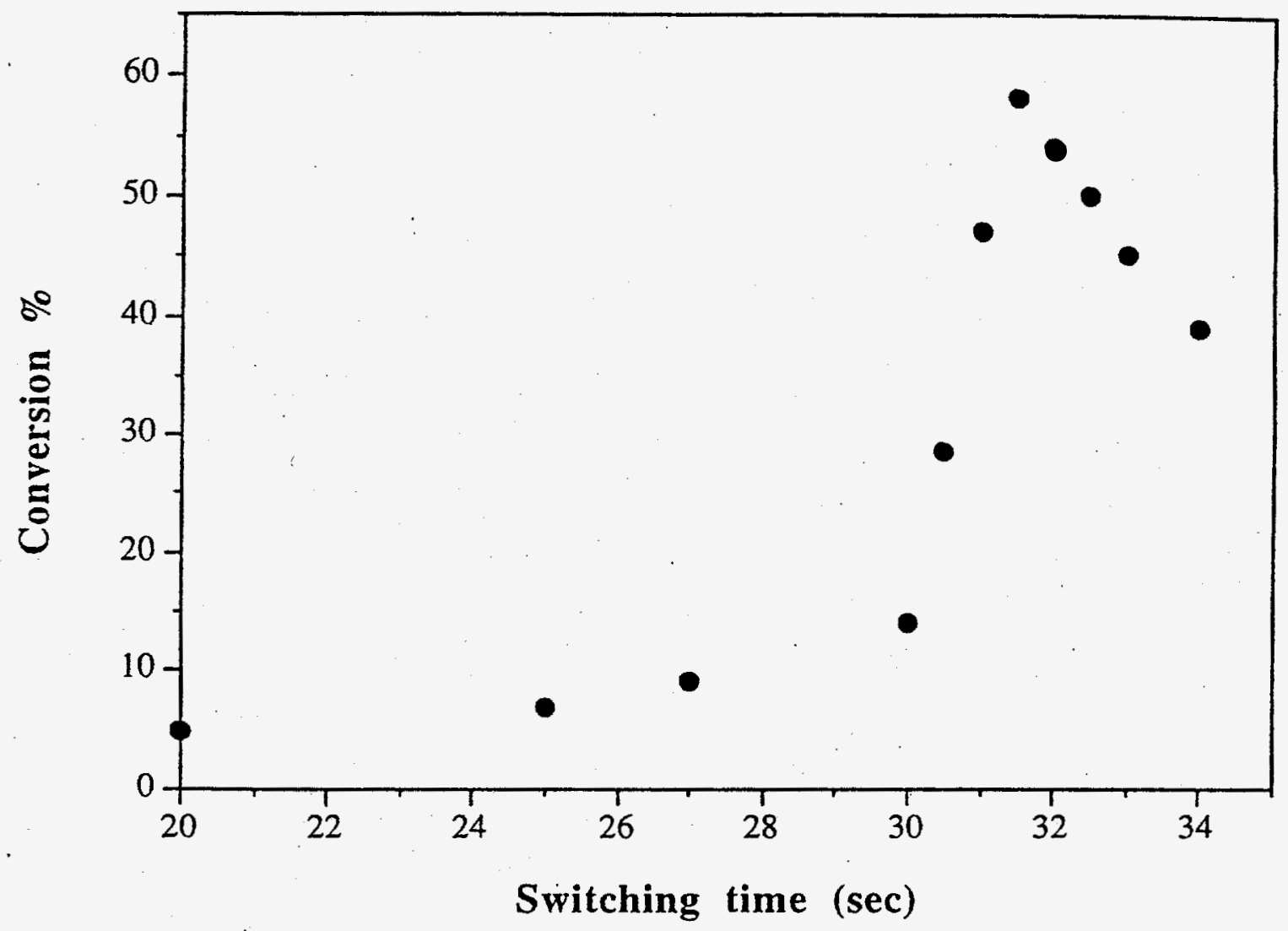

Figure 2: Theoretically predicted conversion as a function of switching time for a breakthrough time of $34 \mathrm{sec}$. 


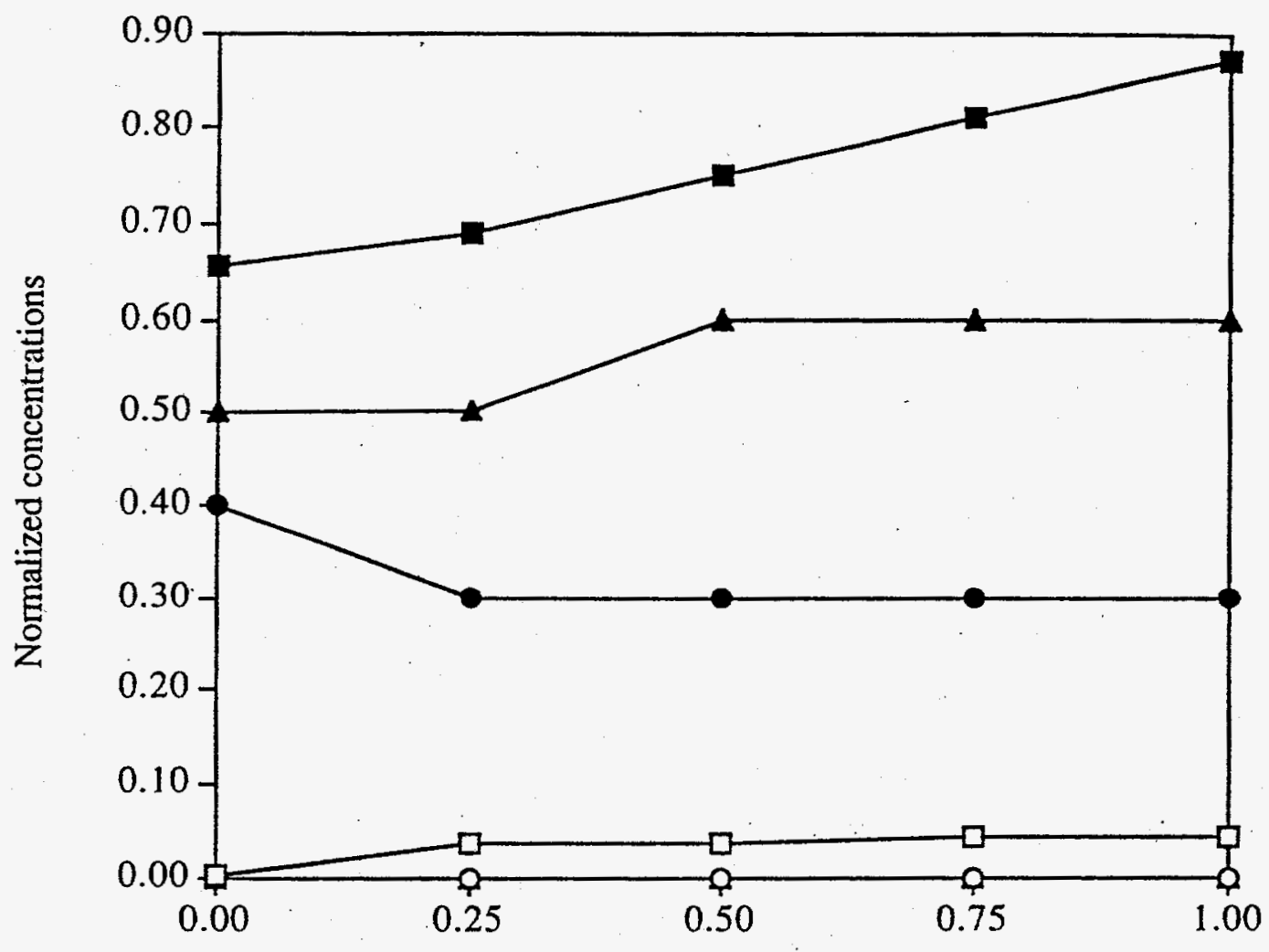

Fraction of reactant column

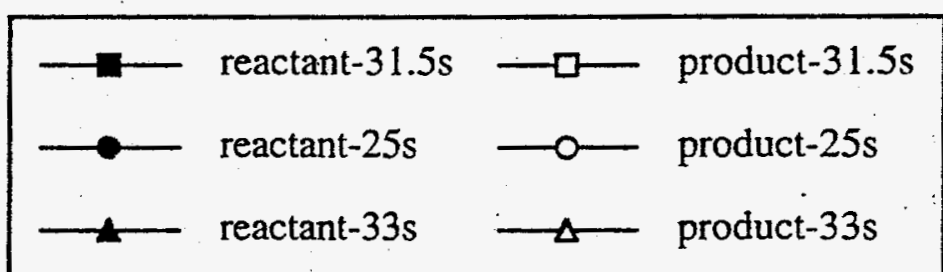

Figure 3: Concentration profiles in reaction column of the feed section. 


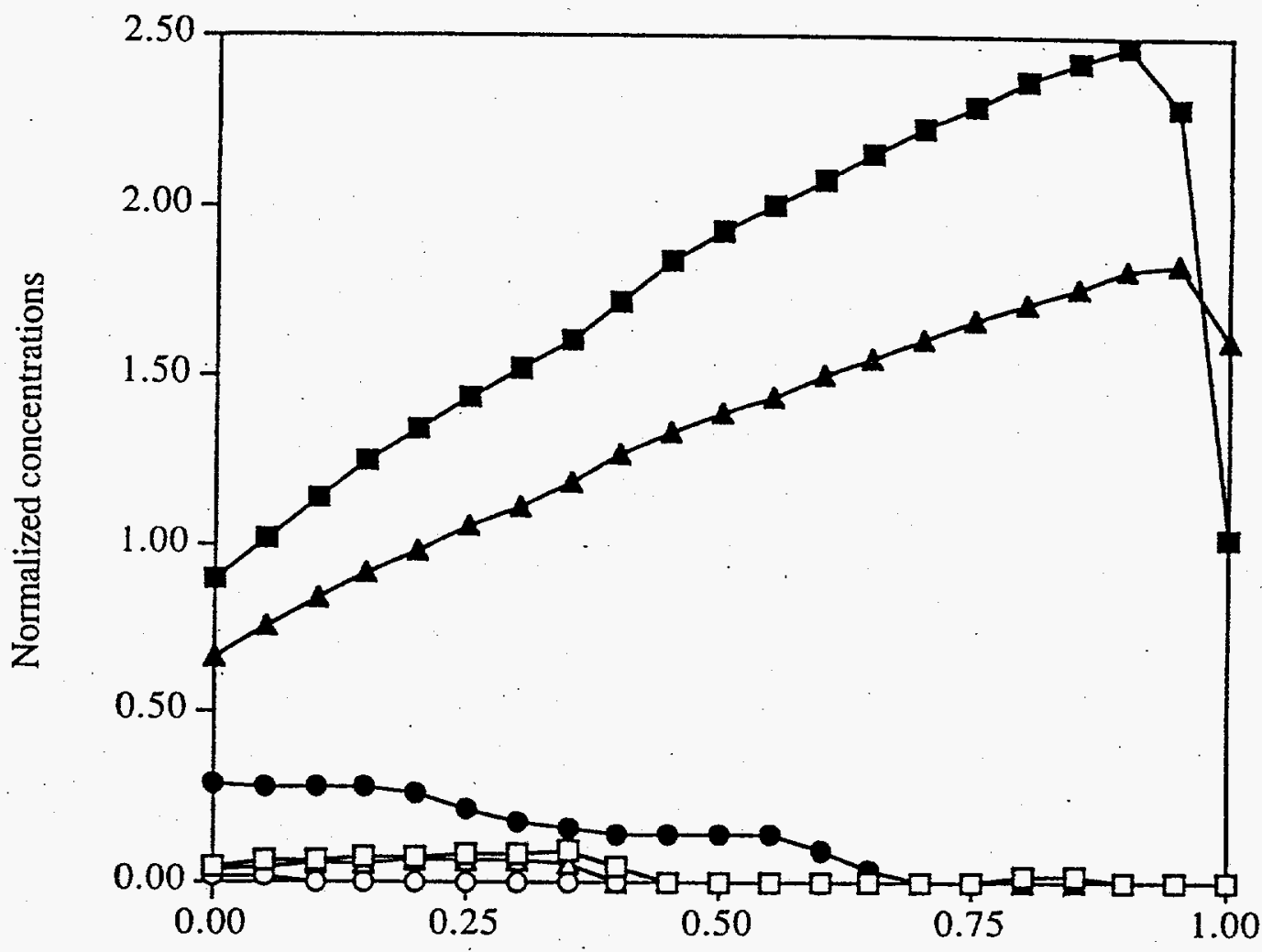

Fraction of separation column

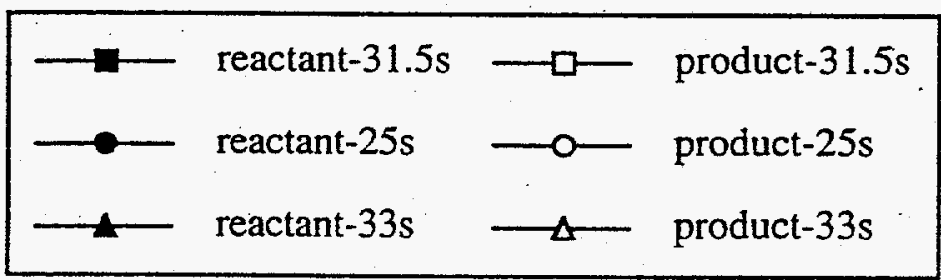

Figure 4: Concentration profiles in the separation column of the feed section. 


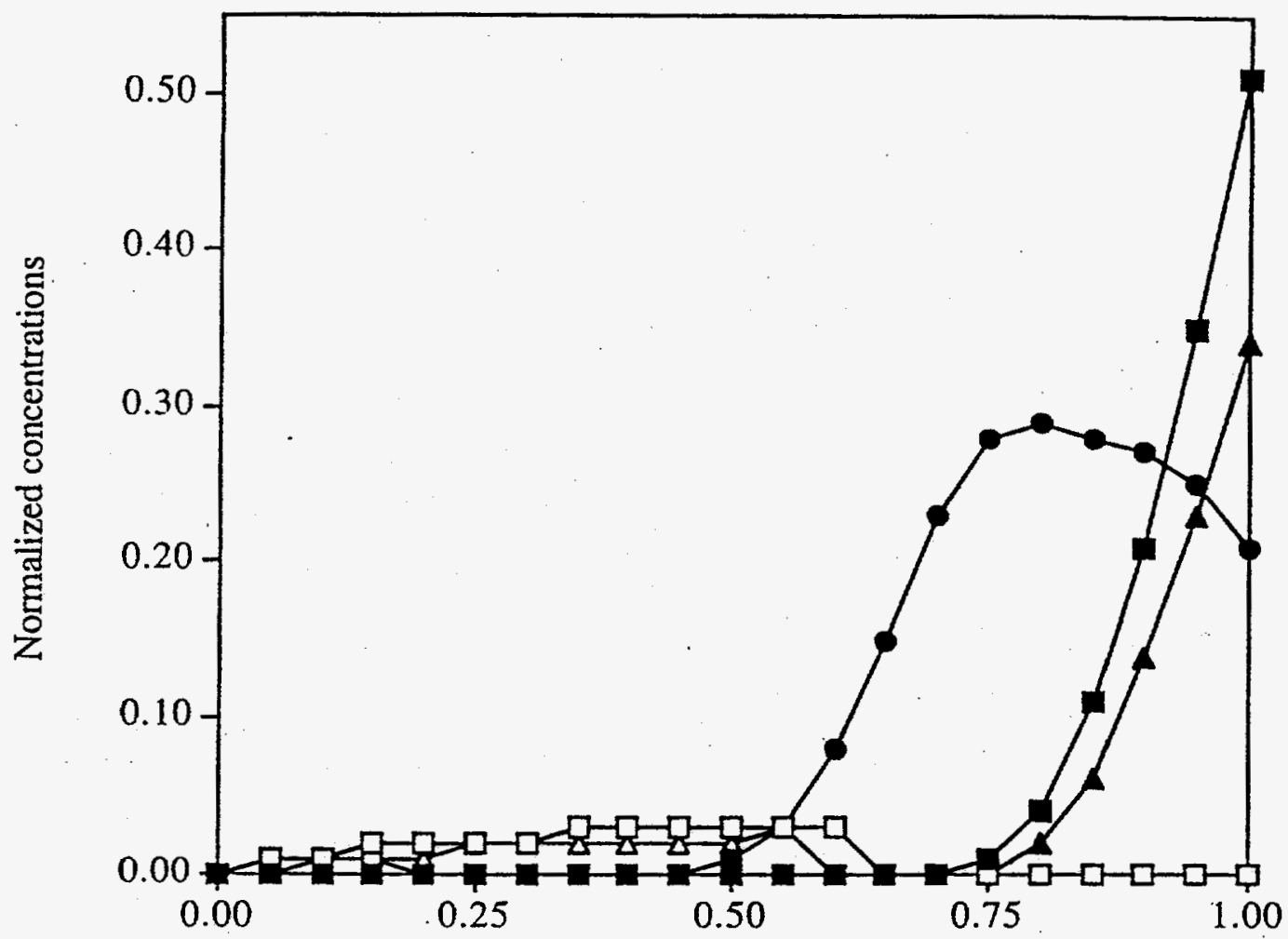

Fraction of separation column

$$
\begin{aligned}
& \longrightarrow \text { Reactant-31.5s } \longrightarrow \text { Reactant-25s } \longrightarrow \text { Product-31.5s } \\
& \longrightarrow \text { Reactant-33s } \rightarrow \triangle \text { Product-25s } \\
& \longrightarrow \text { Product-33s }
\end{aligned}
$$

Figure 5: Concentration profiles in the separation column of the carrier section. 


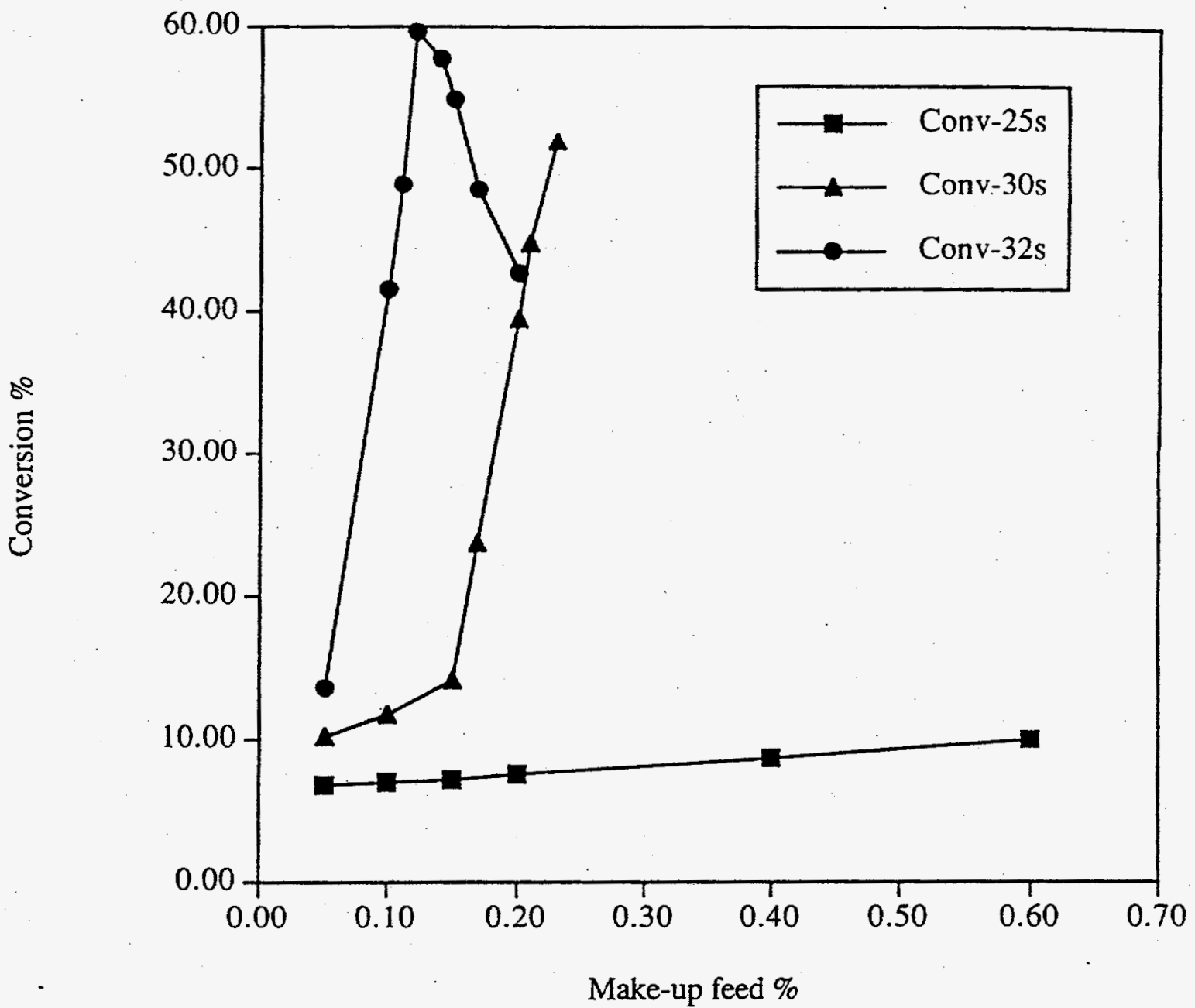

Figure 6: Effect of make-up feed \% for switching times of $25 \mathrm{sec}, 30 \mathrm{sec}$, and $32 \mathrm{sec}$ for a breakthrough time of $34 \mathrm{sec}$. 